\title{
Mechanism of Resistance to the Phosphaturic Effect of the Parathyroid Hormone in the Hamster
}

\author{
Franklyn G. Knox, Josianne Preiss, Jin K. Kim, and Thomas P. Dousa \\ From the Nephrology Research Laboratory, the Departments of Physiology and Biophysics and \\ Medicine, Division of Nephrology, Mayo Clinic and Foundation, Rochester, Minnesota 55901
}

A B S T R A C T The effect of parathyroid hormone and calcitonin on the renal excretion of phosphate, calcium, and cyclic AMP was evaluated in the thyroparathyroidectomized hamster, a mammal apparently resistant to the phosphaturic effect of parathyroid hormone. Parathyroid hormone did not increase phosphate excretion, although it decreased excretion of calcium and increased urinary excretion of cyclic AMP. This lack of a phosphaturic response to parathyroid hormone was not reversed by administration of 25-OH vitamin D or infusions of calcium or phosphate. Calcitonin, another potentially phosphaturic hormone, also failed to increase phosphate excretion but markedly elevated urinary excretion of cyclic AMP. In hamsters pretreated with infusion of ammonium chloride, which decreased plasma and urinary $\mathrm{pH}$, both parathyroid hormone and calcitonin increased excretion of phosphate as well as that of cyclic AMP. Acetazolamide had no phosphaturic effect in ammonium chloride-loaded hamsters, and it decreased cyclic AMP and calcium excretion. Alkalinization of urine by acetazolamide did not prevent the phosphaturic effect of parathyroid hormone in ammonium chloride-loaded hamsters, but it blocked the increase in urinary cyclic AMP excretion. Parathyroid hormone and calcitonin both stimulated adenylate cyclase in a cell-free system (600-g pellet) from hamster renal cortex, elevated tissue cyclic AMP levels, and activated protein kinase in tissue slices from hamster renal cortex. In acid medium, the increase in cyclic AMP and activation of protein kinase in response to parathyroid hormone was diminished, but addition of acetazolamide restored re-

Preliminary results were published in abstract form in 1976: Clin. Res. 24: 36A and Clin. Res. 24: 399A.

Dr. Kim is a fellow of the Minnesota Heart Association. Dr. Dousa is an Established Investigator of the American Heart Association.

Received for publication 26 July 1976 and in revised form 2 November 1976. sponsiveness of both parameters to control values. Acetazolamide, on the other hand, did not influence adenylate cyclase or its response to parathyroid hormone or cyclic AMP phosphodiesterase activity. We conclude that the lack of a phosphaturic effect of parathyroid hormone and calcitonin in the hamster depends on steps in the cellular action of these hormones, steps that are sensitive to $\mathrm{pH}$ subsequent to cyclic AMP generation and protein kinase activation. In addition, acetazolamide may potentiate the phosphaturic effect of parathyroid hormone by promoting accumulation of cyclic AMP in tissue. Thus, the hamster is a particularly useful model for studies of syndromes in which there is renal resistance to phosphaturic hormones.

\section{INTRODUCTION}

Several endocrine syndromes are characterized by resistance of the kidney to the phosphaturic effect of parathyroid hormone (PTH) (1-3). ${ }^{1}$ Investigation of possible mechanisms for end organ resistance have been limited by the lack of a suitable model. Biddulph et al. (4) noticed several years ago that the administration of PTH to hamsters is not followed by the usual drop in plasma levels of phosphate. This suggested the possibility that the hamster is resistant to the phosphaturic effects of PTH. Since it is generally accepted that the phosphaturic effect of PTH is mediated through cyclic $3^{\prime}, 5^{\prime}$-adenosine monophosphate (cAMP) (5), we examined the effects of PTH on renal phosphate handling and on cellular components of the PTH-sensitive cAMP system in

\footnotetext{
'Abbreviations used in this paper: ACZ, acetazolamide; 1-34 bPTH, synthetic 1-34-N-terminal tetratiracontapeptide of bovine parathyroid hormone; cAMP, cyclic 3',5'-adenosine monophosphate; $\mathrm{FEPO}_{4}$, fractional excretion of phosphate; GFR, glomerular filtration rate; MIX, 1-methyl-3isobutyl xanthine; PTH, parathyroid hormone; SCT, salmon calcitonin; TPTX, thyroparathyroidectomized; UVcAMP, urinary cAMP excretion.
} 
hamsters and other closely related mammalian species. A unique dissociation between PTH-dependent cAMP formation and phosphate excretion was found in the hamster which was dependent on the acid-base status of the animal.

\section{METHODS}

\section{Clearance studies}

Male golden Syrian outbread hamsters (ARS, SpragueDawley, Inc., Madison, Wis.), 60-100 g body weight, were maintained on a diet containing $1.2 \%$ calcium, $0.8 \%$ phosphorus, and $16 \mu \mathrm{g} / \mathrm{g}$ vitamin D. Food was withheld $16 \mathrm{~h}$ before experiments. Hamsters had free access to water up to the time of anesthesia. Hamsters were anesthetized with inactin $(130 \mathrm{mg} / \mathrm{kg}$ body weight) and thyroparathyroidectomized (TPTX) $2 \mathrm{~h}$ before clearance studies. A tracheostomy was performed. Catheters were inserted into the jugular vein for an infusion and in the carotid artery for withdrawal of blood and blood pressure monitoring. For collection of urine a catheter was inserted in the base of the bladder with the dome of the bladder ligated. All animals received a priming dose of $0.5 \mathrm{ml}$ inulin $(10 \%)$, and the infusion rate of inulin $(1 \%)$ was kept constant at $0.02 \mathrm{ml} / \mathrm{min}$. The clearances of inulin, phosphate, and calcium were measured in three clearance periods before and after administration of hormones and drugs. 10 experimental protocols were performed.

Group 1: Effect of PTH in TPTX hamsters $(n=8)$. After control clearance periods, $3.3 \mathrm{U} / \mathrm{kg}$ priming dose was given and $1 \mathrm{U} / \mathrm{kg}$ per min synthetic 1-34-N-terminal tetratiracontapeptide of bovine PTH (1-34 bPTH) was infused and experimental clearance periods were initiated $1 \mathrm{~h}$ after beginning the PTH infusion.

Group 2: Effect of PTH in TPTX gerbils $(n=7)$. Parallel experiments were performed in gerbils fed an identical diet and subjected to an identical protocol to evaluate the phosphaturic effect of the 1-34 bPTH in a phylogenetically close species.

Group 3: Effect of PTH in TPTX hamsters pretreated with vitamin $D(n=4)$. Hamsters were injected with $1 \mathrm{mg}$ of 25 $\mathrm{OH}$ vitamin $\mathrm{D}_{3} / 100 \mathrm{~g}$ body weight $10 \mathrm{~h}$ and immediately before anesthesia. The protocol was identical to that utilized in group 1 in other respects.

Group 4: Effect of PTH in TPTX hamsters with control of plasma calcium $(n=7)$. Hypocalcemia was prevented by infusion of calcium chloride at $1 \mathrm{mmol} / \mathrm{min}$ after TPTX and discontinued at the time of administration of PTH.

Group 5: Effect of calcitonin in TPTX hamsters $(n=8)$. After control periods, salmon calcitonin (SCT) $(400 \mathrm{mU} /$ $100 \mathrm{~g}$ ) was administered in a single dose.

Group 6: Effect of PTH in TPTX hamsters which have been made acidotic with ammonium chloride $\left(\mathrm{NH}_{4} \mathrm{Cl}\right)$ $(n=8)$. After control clearances, $\mathrm{NH}_{4} \mathrm{Cl}(150 \mathrm{mM})$ was infused at $2 \mathrm{ml} / \mathrm{h}$ for $60 \mathrm{~min}$. An additional set of clearance periods was then taken in the presence of $\mathrm{NH}_{4} \mathrm{Cl}$ infusion, and then PTH was infused as in the above protocol.

Group 7: Effect of acetazolamide (ACZ) in $\mathrm{NH}_{4} \mathrm{Cl}$-treated TPTX hamsters $(n=6)$. Experiments were performed to evaluate the differential effects of acidemia and aciduria by alkalinizing the urine but maintaining acidemia by the administration of ACZ. Control clearances and clearances during $\mathrm{NH}_{4} \mathrm{Cl}$ administration were collected as in group 5 and then $15 \mathrm{mg} / \mathrm{kg}$ of a priming dose and $15 \mathrm{mg} / \mathrm{kg}$ per h ACZ was infused. Additional clearance periods were initiated shortly after the rapid onset of the ACZ effect.

Group 8: Effect of PTH in TPTX hamsters which were pretreated with $\mathrm{NH}_{4} \mathrm{Cl}$ and $\mathrm{ACZ}(n=6)$. Experiments were conducted to determine if PTH was phosphaturic in the presence of acidemia and alkaline urine. The initial phase of the protocol was identical to that in group 6, with the single exception that urinary losses were replaced by bicarbonate Ringer's solution after ACZ infusion. PTH was then subsequently administered, for which the same protocol was followed as in previous groups.

Group 9: Effect of PTH in TPTX hamsters pretreated with $\mathrm{ACZ}$ alone $(n=7)$. Experiments were conducted to determine if $\mathrm{NH}_{4} \mathrm{Cl}$ pretreatment was necessary to demonstrate the phosphaturic effect of PTH. As in group 7, urinary losses were replaced with bicarbonate Ringer's solution, and identical doses of ACZ and PTH were employed as in the previous protocols.

Group 10: Effect of SCT in TPTX hamsters pretreated with $\mathrm{NH}_{4} \mathrm{Cl}(n=6)$. Experiments were performed to determine if acidemia would uncover a phosphaturic effect of SCT. Studies were performed with an identical protocol to that in group 5 , in which hamsters were pretreated with $\mathrm{NH}_{4} \mathrm{Cl}$ and then SCT was administered in a protocol that was identical to group 4.

Analytic techniques for calcium, phosphate, and inulin determination in plasma and urine have been previously described (6). Inulin in plasma and urine was measured by the anthrone method, phosphate was measured by the Fiske and Subbarow method, and calcium was measured by atomic absorption spectroscopy. Ultrafilterability of plasma phosphate and calcium was determined utilizing Amicon CF 50A membranes (Amicon Corp., Scientific Sys. Div., Lexington, Mass.). Blood pH was determined on a blood-gas analyzer (Instrumentation Laboratory, Inc., Lexington, Mass.). Urine $\mathrm{pH}$ was estimated at the time of collection with phenaphthazine paper and checked with the $\mathrm{pH}$ electrode.

For determination of urinary cAMP excretion, urine was collected in ice and then treated in boiling water bath for $3 \mathrm{~min}(6)$. cAMP in urine was measured by a modified protein binding assay (6). In urine, cAMP was measured without previous purification. The urinary excretion of cAMP was calculated as picomoles of nucleotide excreted per minute relative to glomerular filtration rate (GFR) in milliliters per minute. Although this value does not measure fractional excretion of cAMP, it corrects for variations in total cAMP excretion due to variations in GFR.

\section{Biochemical studies}

For biochemical studies, animals (hamsters, gerbils, and rats) were prepared in an identical fashion to those undergoing clearance studies, including TPTX and anesthesia. $2 \mathrm{~h}$ after surgery, the animals were sacrificed and the kidneys were immersed in ice-cold isotonic sucrose solution and used for the following preparations.

Adenylate cyclase. Cortical and papillary parts of the kidney were dissected from the whole kidney and homogenized in buffered isotonic sucrose medium $(0.25 \mathrm{M}$ sucrose, $5 \mathrm{mM}$ Tris, $3 \mathrm{mM} \mathrm{MgCl}_{2}$, and $1 \mathrm{mM}$ EDTA, $\mathrm{pH} 7.4)$ as previously described $(6,7)$. The $600 \mathrm{~g} / 10$-min pellet of homogenate was washed in a medium of the same composition, divided in small aliquots, frozen in dry ice, and kept frozen at $-80^{\circ} \mathrm{C}$ until assayed for adenylate cyclase activity. Adenylate cyclase activity was assayed as previously described $(6,7)$. In experiments in which the 
effects of added hormones or drugs were tested, the adenylate cyclase activity was measured in the absence and presence of the agent and differences were evaluated on a paired basis. Adenylate cyclase activity was assayed in triplicate and specific enzyme activity was expressed in picomoles of cAMP per minute per milligram of protein.

cAMP phosphodiesterase activity. This was determined in $100,000-g$ supernate (cytosol) or in washed $100,000-g$ pellet membrane fraction (6) of homogenate. cAMP phosphodiesterase activity was measured by incubating the enzyme extract with $1 \mu \mathrm{M}\left[{ }^{3} \mathrm{H}\right] 5^{\prime}$ AMP and was converted to $\left[{ }^{3} \mathrm{H}\right]$ nucleosides by incubation with $5^{\prime}$-nucleotidase as previously described (6). The second incubation was stopped by heating at $95^{\circ} \mathrm{C}$ for $3 \mathrm{~min}$ and nucleoside products were separated from $\left[{ }^{3} \mathrm{H}\right] \mathrm{cAMP}$ on QAE Sephadex columns (Pharmacia Fine Chemicals, Inc., Piscataway, N. J.) according to the procedure of Wells et al. (8). In preliminary experiments we determined that the tested compounds did not interfere with 5'-nucleotidase activity or with the separation of nucleotides on QAE Sephadex columns. The enzyme activity was expressed in picomoles cAMP per minute per milligram of protein. All assays were run in triplicate.

Effect of hormones and drugs on tissue cAMP levels and protein kinase activation. Renal cortical tissue was cut in slices of $0.5-\mathrm{mm}$ thickness with a Stadie-Riggs tissue slicer and thoroughly washed five times in a large volume of ice-cold medium (medium A) of the following composition: $140 \mathrm{mM} \mathrm{NaCl}, 5 \mathrm{mM} \mathrm{KCl}, 1.2 \mathrm{mM} \mathrm{MgSO}_{4}$, $0.8 \mathrm{mM} \mathrm{CaCl}, 10 \mathrm{mM}$ glucose, $10 \mathrm{mM}$ acetic acid, $2 \mathrm{mM}$ sodium phosphate, and $20 \mathrm{mM}$ Tris (pH 7.4).

Measurement of protein kinase activation in intact tissue (in situ). Tissue slices were preincubated in medium A (100 mg of tissue $/ 1.2 \mathrm{ml}$ medium) for $30 \mathrm{~min}$ at $30^{\circ} \mathrm{C}$. Slices were then transferred to fresh medium $\mathrm{A}$ containing $0.5 \mathrm{mM}$ 1-methyl-3-isobutyl xanthine (MIX) and incubated further at $30^{\circ} \mathrm{C}$ for $20 \mathrm{~min}$ without (controls) or with tested agents added at zero incubation time. At the end of the incubation period, slices were removed from the incubation medium, minced with scissors, homogenized in a Teflon-pestle glass homogenizer in $1 \mathrm{ml}$ of a medium B [containing $20 \mathrm{mM} 2-(\mathrm{N}$-morpholine) ethanesulfonic acid, $0.25 \mathrm{M}$ sucrose, $0.5 \mathrm{mM} \mathrm{MIX}$, and $2 \mathrm{mM}$ EDTA, pH 6.0] and filtered through nylon cloth. An aliquot (about $0.2 \mathrm{ml}$ ) of homogenate was immediately mixed with an equal volume of ice-cold $10 \%$ TCA for determination of cAMP. The rest of the homogenate was centrifuged at $40,000 \mathrm{~g}$ for $10 \mathrm{~min}$ and the supernate was immediately frozen in dry ice and later assayed without addition of exogenous cAMP (-cAMP) and another aliquot after addition of exogenous cAMP to a final concentration of 5 $\mu \mathrm{M}(+\mathrm{cAMP})$ to determine the (-cAMP/+cAMP) ratio (9).

Based on the general molecular mechanism of protein kinase activation by CAMP, it has been shown that the ratio of protein kinase activity in fresh tissue extracts measured without added cAMP (-cAMP) to the activity measured with addition of a maximal stimulatory dose of cAMP (+cAMP), the (-cAMP/+cAMP) protein kinase activity ratio, can be used for a semiquantitative assessment of protein kinase activation in intact cells (in situ) (9) including activation by PTH and calcitonin (10). The protein kinase activity ratio was not different whether the $40,000-g$ supernate was assayed immediately after homogenization or after freezing and storing the extract at $-80^{\circ} \mathrm{C}$.

Protein kinase activity. This was assayed in an incubation mixture of $200 \mu \mathrm{l}$ containing the following ingredients in a final concentration: $10 \mathrm{mM} \mathrm{MgCl}_{2}, 2 \mathrm{mM}$ theophyl- line, $0.3 \mathrm{mM}$ ethylene glycol bis $(\beta)$-aminoethyl ether tetraacetic acid, $10 \mathrm{mM} \mathrm{NaF}, 2.5 \mu \mathrm{M}$ [ $\left.{ }^{32} \mathrm{P}-\gamma\right]$ ATP $\left(2-3 \times 10^{6}\right.$ cpm per tube), $75 \mu \mathrm{g}$ of $\mathrm{f}_{2 \mathrm{~b}}$ fraction of calf thymus histones (Sigma Chemical Co., St. Louis, Mo.), and $50 \mathrm{mM}$ sodium $\beta$-glycerophosphate ( $\mathrm{pH}$ 6.5). The incubation was started by addition of $10 \mu \mathrm{l}$ of the enzyme extract containing 8-15 $\mu \mathrm{g}$ of protein per tube, and the incubation was carried out for $5 \mathrm{~min}$ at $30^{\circ} \mathrm{C}$; it was terminated by adding $1 \mathrm{ml}$ of $10 \%$ TCA. The ${ }^{32} \mathrm{P}$ incorporated into the protein was measured by the procedure as described in our previous experiments (7). The final TCA protein precipitate was collected on glass fiber filters (GF/C Whatman, Inc., Clifton, N. J.) and ${ }^{32} \mathrm{P}$ was determined by liquid scintillation counting. In the above-described enzyme extract (prepared in medium B), the protein kinase activity was linear with protein at least up to $25 \mu \mathrm{g}$ per tube and was linear with time for at least $8 \mathrm{~min}$. The $\mathrm{f}_{2 b}$ fraction (Sigma Chemical Co.) was a more effective substrate than the mixed histones type II-A, and phosphorylation was markedly stimulated by cAMP. With the $f_{2 b}$ fraction as a substrate, the maximal stimulation by cAMP was at concentrations of $1 \mu \mathrm{M}-0.01 \mathrm{mM}$. The autoincorporation was minimal and therefore was not routinely measured and subtracted (11). Protein kinase assays were run in triplicate.

cAMP determination. To measure cAMP in tissue extracts in which proteins were precipitated by TCA, the protein precipitate was first removed by centrifugation at $10^{-4} \mathrm{~g}$ for $10 \mathrm{~min}$ and TCA extracted with water-saturated ethyl ether. cAMP in the TCA-free extract was then determined by the radioimmunoassay of Steiner (12). The results are expressed in picomoles of cAMP per milligram of tissue protein. cAMP content in urine was measured without further purification with a modified competitive protein binding assay as described above (6).

Protein determination. This was performed by the method of Lowry et al. after solubilization of samples in $1 \%$ sodium lauryl sulfate $(7)$.

\section{Materials}

1-34 bPTH (activity 4,000-6,000 IU/mg) was supplied by Beckman Instruments, Inc., Spinco Div., Palo Alto, Calif.; SCT (sp act 2,300 MRC/mg) was purchased from Calibiochem, San Diego, Calif.; [ $\left.{ }^{32} \mathrm{P}-\gamma\right]$ ATP and $\left[{ }^{32} \mathrm{P}-\alpha\right]$ ATP were products of International Nuclear Corp., Irvine, Calif.; $\left[{ }^{3} \mathrm{H}\right] \mathrm{cAMP}$ and cAMP radioimmunoassay kits were purchased from New England Nuclear, Boston, Mass. Synthetic [8-arginine]-vasopressin, histones ( $f_{2 b}$ fraction), ACZ, and cAMP were supplied by Sigma Chemical Co.; MIX was obtained from Aldrich Chemical Co., Milwaukee, Wis. All chemicals and biochemicals were of highest purity grades.

Results were evaluated by Student's $t$ test for either group or paired comparison as appropriate.

\section{RESULTS}

\section{Clearance studies}

The results for all 10 groups of clearance studies are summarized in Tables I and II. Plasma phosphate was freely ultrafilterable and plasma calcium was $55 \pm 3 \%$ ultrafilterable in hamsters. Mean arterial blood pressure averaged $121 \mathrm{~mm} \mathrm{Hg}$, was not sig- 
TABLE I

Clearance Data from Animals in Normal Acid-Base Balance

\begin{tabular}{|c|c|c|c|c|c|c|c|c|c|c|c|c|c|c|c|c|}
\hline \multirow[b]{3}{*}{ Group } & \multirow{3}{*}{\multicolumn{2}{|c|}{ Protocol }} & \multirow{2}{*}{\multicolumn{2}{|c|}{ GFR }} & \multirow{2}{*}{\multicolumn{2}{|c|}{$\mathrm{FEPO}_{4}$}} & \multirow{2}{*}{\multicolumn{2}{|c|}{$\mathrm{FE}_{\mathrm{Ca}}$}} & \multirow{2}{*}{\multicolumn{2}{|c|}{$\frac{\text { UVCAMP }}{\text { GFR }}$}} & \multicolumn{6}{|c|}{ Plasma } \\
\hline & & & & & & & & & & & \multicolumn{3}{|c|}{$P$} & \multicolumn{3}{|c|}{$\mathrm{Ca}$} \\
\hline & & & C & E & C & $\mathrm{E}$ & C & E & C & E & $\mathrm{N}$ & C & E & $\mathrm{N}$ & C & E \\
\hline & & & & & & & & & & & & & & $M$ & & \\
\hline \multirow[t]{3}{*}{1} & $\begin{array}{l}\text { TPTX } \\
\text { (han }\end{array}$ & $\begin{array}{l}\text { PTH } \\
\text { ster) }\end{array}$ & 14 & 12 & 14 & 9 & 9 & 6 & 313 & 699 & & 1.9 & 1.8 & 2.2 & 1.6 & 1.8 \\
\hline & SE & & 1 & 1 & 4 & 3 & 2 & 1 & 92 & 88 & & 0.2 & 0.2 & & 0.1 & \\
\hline & $P ; n$ & & & & & & & & $<0$ & & & NS; 7 & & NS & $3<0.0$ & $5 ; 6$ \\
\hline \multirow[t]{2}{*}{2} & $\begin{array}{r}\text { TPTX } \\
\text { (ge }\end{array}$ & $\begin{array}{l}\text { PTH } \\
\text { iil) }\end{array}$ & 11 & 13 & 3 & 19 & 2 & 1 & 28 & 288 & 1.9 & 2.3 & 2.0 & 1.9 & 1.5 & 1.7 \\
\hline & $\begin{array}{l}S E \\
P ; n\end{array}$ & & & $7^{2}$ & $\begin{array}{r}1 \\
<0 .\end{array}$ & $\begin{array}{r}2 \\
1 ; 7\end{array}$ & 0. & $7^{0.2}$ & $\begin{array}{r}4 \\
<0\end{array}$ & $\begin{array}{c}82 \\
5 ; 7\end{array}$ & $<0$. & $\begin{array}{r}0.2 \\
25 ; 7\end{array}$ & $\begin{array}{r}0.2 \\
\mathrm{NS} ; 7\end{array}$ & $\begin{array}{l}0.1 \\
<0\end{array}$ & $\begin{array}{r}0.1 \\
005 ; 7\end{array}$ & $\begin{array}{r}0.1 \\
\text { NS; } 7\end{array}$ \\
\hline \multirow[t]{2}{*}{3} & $\begin{array}{r}\text { TPTX } \\
+\mathrm{D}\end{array}$ & $\begin{array}{l}\text { PTH } \\
\quad+\text { D }\end{array}$ & 8 & 9 & 14 & 8 & 16 & 2 & 90 & 153 & 1.4 & 1.5 & 1.4 & 1.4 & 1.4 & 1.5 \\
\hline & $\begin{array}{c}\text { SE } \\
P ; n\end{array}$ & & & $4^{1}$ & & $4^{3}$ & 6 & $3^{1}$ & $\begin{array}{l}33 \\
<0\end{array}$ & $\begin{array}{l}30 \\
2 ; 4\end{array}$ & $\begin{array}{l}0.2 \\
\mathrm{~N}\end{array}$ & $\begin{array}{r}0.3 \\
44 \mathrm{~N}\end{array}$ & 0.1 & $\begin{array}{c}0.2 \\
<0\end{array}$ & $\begin{array}{c}0.3 \\
02 ; 4 \mathrm{~N}\end{array}$ & $\begin{array}{c}0.3 \\
S ; 4\end{array}$ \\
\hline \multirow[t]{2}{*}{4} & $\begin{array}{l}\text { TPTX } \\
\quad+\mathrm{Ca}\end{array}$ & PTH & 11 & 9 & 9 & 7 & 16 & 2 & 63 & 143 & 2.1 & 1.8 & 2.1 & 2.2 & 3.3 & 2.4 \\
\hline & $\begin{array}{c}\text { SE } \\
P ; n\end{array}$ & & $\begin{array}{c}1 \\
<0\end{array}$ & $\begin{array}{c}1 \\
25 ; 7\end{array}$ & & & & $\begin{array}{c}0.2 \\
5 ; 5\end{array}$ & & & $\begin{array}{r}0.4 \\
\mathrm{~N}\end{array}$ & 0.2 & 0.3 & $\begin{array}{r}0.1 \\
<-0 .\end{array}$ & $\begin{array}{c}0.4 \\
5 ; 7<0\end{array}$ & $\begin{array}{r}0.2 \\
.05 ; 7\end{array}$ \\
\hline \multirow[t]{2}{*}{5} & TPTX & SCT & 14 & 13 & 13 & $\begin{array}{r}12 \\
4\end{array}$ & 11 & $\begin{array}{r}13 \\
2\end{array}$ & 243 & 825 & 1.2 & 1.4 & 1.2 & 2.3 & 1.6 & \\
\hline & $P ; n$ & & & & & & & & & & & $; 2 \mathrm{~N}$ & & $<0$ & $001 ; 8$ I & NS;8 \\
\hline
\end{tabular}

Abbreviations: GFR, glomerular filtration rate as determined from the clearance of inulin; UVcAMP/GFR, urinary excretion of cAMP corrected for GFR; $F_{\mathrm{Ca}}$, fractional excretion of calcium; $\mathrm{C}$, mean of control clearance periods; $\mathrm{E}$, mean of clearance periods after experimental infusions; N, value before TPTX; $n$, number of observations. For other abbreviations, see Footnote 1.

nificantly different between groups, and was not significantly changed within experimental protocols.

Group 1. Effect of PTH in hamsters. PTH was not phosphaturic; indeed, fractional phosphate excretion $\left(\mathrm{FEPO}_{4}\right)$ was significantly decreased after PTH. Although the phosphaturic effect of PTH was not observed, urinary excretion of cAMP (UVcAMP) was markedly increased, and the fractional excretion of calcium was significantly decreased.

Group 2. The administration of PTH to the TPTX gerbil resulted in a marked phosphaturia in association with a significant increase in UVcAMP.

Group 3. The administration of PTH to the TPTX hamster that was pretreated with vitamin $\mathrm{D}$ did not uncover a phosphaturic effect of PTH, whereas the UVcAMP was significantly increased. The urinary excretion of calcium was $16 \pm 6 \%$ in control periods and $2 \pm 1 \%$ after PTH. However, with the small number of observations in this group and the variability of the changes, this did not reach a level of statistical significance.

Group 4. The administration of PTH to the TPTX hamster in which hypocalcemia was prevented did not uncover a phosphaturic effect of PTH. Basal excretion (before PTH infusion) of phosphate and cAMP was significantly $(P<0.05)$ lower than in animals with hypocalcemia (group 1). This is in accord with the observation that increases in plasma calcium blunt the $\mathrm{FEPO}_{4}$ and cAMP $(13,14)$. Administration of PTH significantly increased UVcAMP, decreased calcium excretion, but failed to produce phosphaturia.

Group 5. Administration of SCT to the TPTX hamster had no significant effects on urinary excretions of phosphate or calcium but significantly increased the urinary excretion of cAMP.

Group 6. The administration of PTH to the TPTX hamster that was pretreated with $\mathrm{NH}_{4} \mathrm{Cl}$ resulted in unmasking a marked phosphaturic effect of PTH. This was accompanied by significant decreases in the urinary excretion of calcium and significant increases in UVcAMP. It is important to note that $\mathrm{NH}_{4} \mathrm{Cl}$ pretreatment lowered $\mathrm{FEPO}_{4}$ in a manner similar to that seen with calcium infusions (group 4).

Group 7. The administration of ACZ to TPTX hamsters made acidotic with $\mathrm{NH}_{4} \mathrm{Cl}$ did not have a 


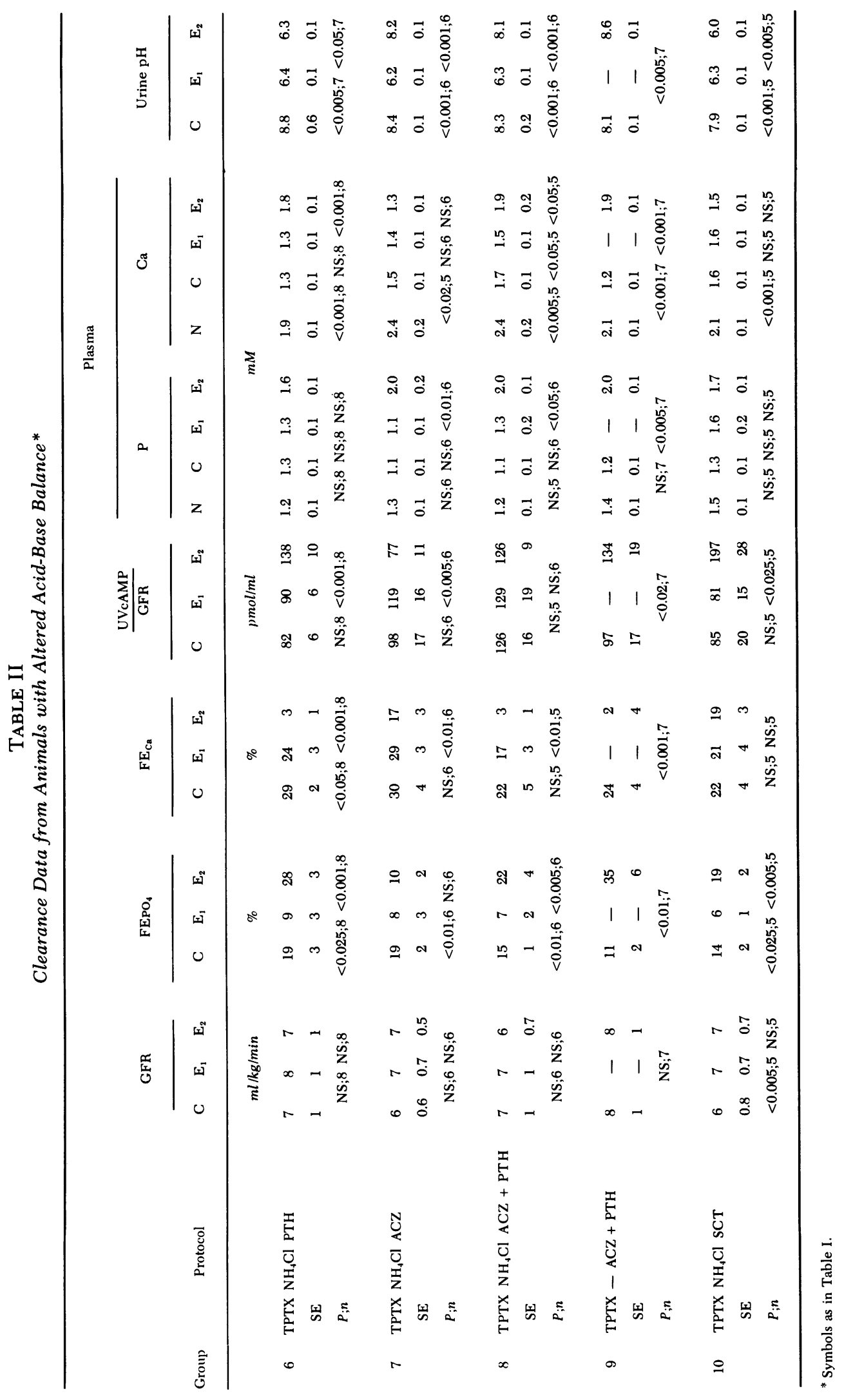


TABLE III

Hormonal Responsiveness of Hamster Renal Adenylate Cyclase to PTH, SCT, [8-Arg] Vasopressin (AVP), and Sodium Fluoride (NaF)

Adenylate cyclase activity, $\mathrm{pmol}$ cAMP/min/mg protein

$\begin{array}{llll}\text { Cortex } & P^{*} & \text { Papilla } & P^{*}\end{array}$

\begin{tabular}{lcccc}
\hline Basal activity & $10.8 \pm 8.4 \ddagger$ & & $32.2 \pm 5.3$ & \\
PTH $(10 \mu \mathrm{g} / \mathrm{ml})$ & $44.6 \pm 1.8$ & $<0.001$ & $30.3 \pm 4.8$ & NS \\
SCT $(3 \mu \mathrm{g} / \mathrm{ml})$ & $28.6 \pm 0.9$ & $<0.001$ & $32.8 \pm 5.3$ & NS \\
AVP $(1 \mu \mathrm{M})$ & $19.8 \pm 1.2$ & $<0.001$ & $125.1 \pm 6.6$ & $<0.001$ \\
NaF $(1 \mathrm{cM})$ & $109.8 \pm 2.9$ & $<0.001$ & $196.5 \pm 16.5$ & $<0.001$
\end{tabular}

* For significance of difference from basal activity (paired $t$ test).

$\ddagger$ Mean \pm SE from six experiments.

significant effect on the fractional excretion of phosphate. The fractional excretion of calcium was significantly decreased after ACZ, as was the urinary UVcAMP. The urine was significantly acidified by $\mathrm{NH}_{4} \mathrm{Cl}$ and subsequently significantly alkalinized by ACZ.

Group 8. The administration of PTH and ACZ in combination to TPTX hamsters pretreated with $\mathrm{NH}_{4} \mathrm{Cl}$ resulted in a marked phosphaturia. Similarly, the fractional excretion of calcium was significantly decreased, but interestingly, UVcAMP was not significantly changed. Urine $\mathrm{pH}$ significantly decreased with $\mathrm{NH}_{4} \mathrm{Cl}$ pretreatment and then was significantly increased after combined ACZ and $\mathrm{PTH}$ administration. Blood $\mathrm{pH}$ averaged $7.5 \pm 0.05$ in the control period and was significantly decreased to $7.19 \pm 0.05$ after $\mathrm{NH}_{4} \mathrm{Cl}$ treatment $(-\Delta 0.26 \pm 0.04$, $P<0.005)$. After combined administration of $\mathrm{ACZ}$ and $\mathrm{PTH}$, blood $\mathrm{pH}$ remained acid at $\mathrm{pH}$ $6.9 \pm 0.2$, a value not significantly different from that after $\mathrm{NH}_{4} \mathrm{Cl}$ administration alone $(-\Delta 0.28 \pm 0.14)$.
Group 9. Administration of ACZ and PTH in combination to TPTX hamsters resulted in a significant increase in $\mathrm{FEPO}_{4}$, increase in UVcAMP, and decrease in fractional excretion of calcium. Urine pH was alkaline in control periods and became slightly but significantly more alkaline after ACZ administration. In contrast, plasma $\mathrm{pH}$ significantly decreased from $7.5 \pm 0.02$ in control periods to $7.2 \pm 0.02$ after combined administration of ACZ and PTH $(\Delta 0.3 \pm 0.003, P<0.001, n=7)$.

Group 10. Pretreatment with $\mathrm{NH}_{4} \mathrm{Cl}$ unmasked a significant phosphaturic effect of SCT in TPTX hamsters, and the UVcAMP was significantly increased. There were no significant changes in fractional excretion of calcium. Urine $\mathrm{pH}$ was significantly acidified by $\mathrm{NH}_{4} \mathrm{Cl}$ and was slightly but significantly further acidified after SCT administration. The $\mathrm{pH}$ of the blood was significantly decreased after $\mathrm{NH}_{4} \mathrm{Cl}$ administration, from $7.5 \pm 0.06$ to 7.2 $\pm 0.03(\Delta 0.23 \pm 0.04, P<0.005, n=5)$. After SCT administration blood $\mathrm{pH}$ was slightly but significantly further decreased $(\Delta 0.1 \pm 0.04, P<0.05, \mathrm{n}=5)$.

\section{In vitro studies}

The hormonal responsiveness of adenylate cyclase from the hamster kidney is summarized in Table III. Adenylate cyclase activity in preparations from cortex increased significantly after addition of PTH or SCT. In contrast, neither hormone had significant effects on adenylate cyclase activity in preparations from the papilla. For comparison, vasopressin had a small but significant stimulatory effect in the renal cortex and a marked stimulatory effect in the papilla.

Since ACZ markedly influenced the phosphaturic response to PTH in the hamster, the effects of PTH and ACZ, alone or in combination, were tested on renal cortical adenylate cyclase from hamsters, gerbils,

TABLE IV

Effects of PTH, Acetazolamide, and SCT on Renal Cortical Adenylate Cyclase from Hamster, Gerbil, and Rat

\begin{tabular}{|c|c|c|c|c|c|c|c|}
\hline & & \multirow[b]{2}{*}{ Basal activity } & \multirow[b]{2}{*}{ PTH, $10 \mu \mathrm{g} / \mathrm{ml}$} & \multicolumn{2}{|c|}{ Acetazolamide } & \multirow{2}{*}{$\begin{array}{c}\text { PTH with } \\
\text { acetazolamide, } 0.1 \mathrm{mM}\end{array}$} & \multirow[b]{2}{*}{$\mathrm{SCT}, 3 \mu \mathrm{g} / \mathrm{ml}$} \\
\hline & & & & $0.01 \mathrm{mM}$ & $0.1 \mathrm{mM}$ & & \\
\hline Rats & $(6)^{*}$ & $4.09 \pm 0.28 \ddagger$ & $12.46 \pm 1.06 \S$ & $4.1 \pm 0.34$ & $4.51 \pm 0.43$ & - & - \\
\hline Gerbils & (5) & $3.41 \pm 0.18$ & $8.28 \pm 0.13 \S$ & - & $3.79 \pm 0.34$ & - & $4.44 \pm 0.21 \rrbracket$ \\
\hline Hamsters & (4) & $7.38 \pm 0.27$ & $21.95 \pm 1.73 \S$ & - & $8.88 \pm 1.09$ & $22.3 \pm 1.27 \|$ & - \\
\hline
\end{tabular}

Adenylate cyclase activity was measured in $600-\mathrm{g}$ pellet of homogenate and activity expressed in picomoles of cAMP per minute per milligram of protein.

* Number of experiments in parentheses.

$\ddagger$ Mean \pm SE.

\$ Significantly different from basal activity (paired $t$ test) at $P<0.005$.

"Significantly different from basal activity at $P<0.001$ but not significantly different from PTH alone.

II Significantly different from basal activity (paired $t$ test) at $P<0.01$. 
TABLE V

Changes in Tissue Cyclic AMP Levels and In Situ Activation of Protein Kinase in Renal Cortical Slices from Rat and Hamster

\begin{tabular}{|c|c|c|c|c|c|}
\hline & \multicolumn{3}{|c|}{ Hamsters } & \multicolumn{2}{|c|}{ Rats } \\
\hline & Basal & PTH & SCT & Basal & PTH \\
\hline $\begin{array}{l}\text { cAMP level, pmol cAMP/ mg protein } \\
\text { Increase, \% } \\
\text { (-cyclic AMP/+cyclic AMP) } \\
\text { Protein kinase activity ratio } \\
\text { Increase, } \%\end{array}$ & $\begin{array}{l}34.2 \pm 2.9^{*} \\
0.16 \pm 0.01\end{array}$ & $\begin{array}{l}88.5 \pm 5.0 \ddagger \\
167 \pm 20 \\
0.35 \pm 0.02 \ddagger \\
122 \pm 13\end{array}$ & $\begin{array}{c}70.8 \pm 8.7 \S \\
118 \pm 34 \\
0.27 \pm 0.02 \\
74 \pm 11\end{array}$ & $\begin{array}{c}16.8 \pm 2.4 \\
0.38 \pm 0.05\end{array}$ & $\begin{array}{c}40.8 \pm 3.8 \ddagger \\
185 \pm 36 \\
0.75 \pm 0.05 t\end{array}$ \\
\hline
\end{tabular}

The extent of protein kinase activation or elevation in tissue level of cAMP after PTH (in terms of percent increase) was not significantly different between rat and hamster. Activation of protein kinase in hamster cortex slices was significantly different between rat and hamster. Activation of protein kinase in hamster cortex slices was significantly lower with SCT than with PTH. Concentrations of PTH $(10 \mu \mathrm{g} / \mathrm{ml})$ and SCT $(30 \mu \mathrm{g} / \mathrm{ml})$ were those which elicited maximal stimulation of adenylate cyclase in cell-free system. For experimental conditions, see Methods. Experiments were done on 7 preparations from hamsters and 10 from rats.

* Mean \pm SE.

‡ Significantly different from basal value at $P<0.001$ (paired $t$ test).

$\S$ Significantly different from basal value at $P<0.005$ (paired $t$ test).

and rats (Table IV). PTH increased adenylate cyclase activity approximately threefold in each species. In contrast, ACZ had no significant effect on basal adenylate cyclase activity. When PTH and ACZ were added together, there was no significant difference between the response observed after addition of PTH alone. ACZ had no effect on the activity of cAMP phosphodiesterase from hamster cortex in cytosol or in the $100,000-g$ pellet.

The effect of PTH on in situ activation of protein kinase and changes in tissue cAMP levels were studied in renal cortical slices from rats and hamsters (Table V). cAMP levels were significantly increased after either PTH or SCT when these were added to renal cortical slices from hamsters. Similarly, cAMP levels in renal cortical slices from rats were significantly increased after addition of PTH. The $(-c A M P /+c A M P)$ protein kinase activity ratio was significantly increased after PTH or SCT in ham- sters and after PTH in rats. Although basal levels differed between rats and hamsters, the percent increases in protein kinase activity ratio after PTH were similar.

The effect of $\mathrm{pH}, \mathrm{NH}_{4} \mathrm{Cl}$, and $\mathrm{ACZ}$ on levels of cAMP and activation of protein kinase activity in response to PTH in tissue slices is summarized in Table VI. The basal tissue levels of cAMP and basal $(-\mathrm{cAMP} /+\mathrm{cAMP})$ protein kinase ratios were the same in the three media and were significantly increased by PTH in all three media. However, the magnitude of the increase in the tissue cAMP level and the magnitude of the protein kinase activation after $\mathrm{PTH}$ in the acid media plus $\mathrm{NH}_{4} \mathrm{Cl}$ were significantly less than that seen in the media with normal $\mathrm{pH}$. When ACZ was added to the acid medium with $\mathrm{NH}_{4} \mathrm{Cl}$, the increase in cAMP levels and protein kinase activation was indistinguishable from controls at $\mathrm{pH} 7.4$ without $\mathrm{NH}_{4} \mathrm{Cl}$ and ACZ.

TABLE VI

Effect of $\mathrm{pH}, \mathrm{NH}_{4} \mathrm{Cl}$, and Acetazolamide on Tissue Levels of cAMP and Activation of the Protein Kinase in Response to PTH

\begin{tabular}{|c|c|c|c|c|c|c|c|c|c|}
\hline & \multicolumn{3}{|c|}{ Medium A } & \multicolumn{3}{|c|}{ Medium B } & \multicolumn{3}{|c|}{ Medium C } \\
\hline & Control & PTH & $\Delta \%$ & Control & PTH & $\Delta \%$ & Control & PTH & $\Delta \%$ \\
\hline $\begin{array}{l}\text { Tissue, cAMP level, } \\
\text { pmol/mg protein }\end{array}$ & $16.7^{*} \pm 2.3$ & $63.1 \pm 11.6$ & $284 \pm 42$ & $19.4 \pm 2.2$ & $46.7 \pm 6.5$ & $+138 \pm 8 t$ & $14.0 \pm 1.8$ & $62.5 \pm 10.3$ & $365 \pm 80$ \\
\hline $\begin{array}{l}\text { Protein kinase activity ratio } \\
\text { (-cyclic AMP/+cyclic AMP) }\end{array}$ & $0.18^{*} \pm 0.01$ & $0.39 \pm 0.05$ & $118 \pm 19$ & $0.20 \pm 0.02$ & $0.34 \pm 0.05$ & $66 \pm 14 \S$ & $0.18 \pm 0.01$ & $0.40 \pm 0.04$ & $125 \pm 17$ \\
\hline
\end{tabular}

Basal medium (modified Krebs-Ringer solution) is described in Methods. Medium A: Krebs-Ringer, pH = 7.4. $\mathrm{Medium} \mathrm{B:} \mathrm{Krebs}-\mathrm{Ringer}, \mathrm{pH}=7.0,+20 \mathrm{mM}$ NH4 $\mathrm{Cl}$ Medium C: Krebs-Ringer, $\mathrm{pH}=7.0,+20 \mathrm{mM} \mathrm{NH} \mathrm{Nl}_{4}+0.1 \mathrm{mM}$ acetazolamide. Response to PTH in medium $\mathrm{A}$ vs. B and B vs. C was always assessed in paired experiment $(n=6-8)$. The basal specific enzyme activity of protein kinase was $18.2 \pm 1.2$ in medium $A, 18.6 \pm 0.8$ in medium $B$, and $17.8 \pm 1.1$ in medium $C$.

* Mean \pm SE

t Significantly different from both $A$ and $C ; P<0.05$ (paired $t$ test).

$\$$ Significantly different from both $A$ and $C ; P<0.01$ (paired $t$ test). 


\section{DISCUSSION}

Infusion of 1-34 bPTH was not phosphaturic in the TPTX hamster although fractional excretion of calcium was significantly decreased and UVcAMP was significantly increased. Administration of PTH to the gerbil or rat, phylogenetically close species, resulted in marked phosphaturia and increases in UVcAMP. In additional experiments, we ruled out the possibilities that the resistance to PTH was due to vitamin $\mathrm{D}$ deficiency or hypocalcemia. The functional findings of increased UVcAMP without phosphaturia in response to PTH have been described in experimentally induced severe phosphate depletion (15). In the present studies, animals were on a normal phosphate diet $(0.8 \%)$ and after TPTX had a usually high $\mathrm{FEPO}_{4}$ rather than low $\mathrm{FEPO}_{4}$ as expected if there were severe chronic phosphate depletion. To rule out a role for acute phosphate depletion, several additional hamsters were phosphate loaded. Elevation of plasma phosphate levels to $4 \mathrm{mM}$ failed to unmask a phosphaturic effect of PTH. The failure to demonstrate a phosphaturic effect of PTH in the hamster was not due to a defect in stimulation of adenylate cyclase, accumulation of cAMP in the renal cortex, or activation of protein kinase, which are considered initial steps in the cellular action of PTH in the kidney. Accordingly, the absence of a phosphaturic effect of PTH is due to a defect beyond these steps.

We evaluated the effects of SCT in the hamster to determine whether another polypeptide hormone that is phosphaturic in the rat (16) and gerbil (Knox and Dousa. Unpublished observations.) would give similar results to those seen with PTH. As illustrated in group 5, SCT also was not phosphaturic, although it markedly increased UVcAMP, stimulated adenylate cyclase, elevated tissue cAMP, and activated protein kinase in vitro. These observations suggest that the lack of a phosphaturic response to SCT is due to a defect in steps of cellular hormone action subsequent to cAMP generation and protein kinase activation as was the case for PTH.

Since hamsters have markedly alkaline urine, we explored the effects of $\mathrm{pH}$ on the phosphaturic effect of PTH. As illustrated in group 6, $\mathrm{NH}_{4} \mathrm{Cl}$-induced acidosis resulted in significant decreases in $\mathrm{FEPO}_{4}$ in the TPTX hamster, and then the subsequent administration of PTH was markedly phosphaturic. This finding raised the question whether the restoration of the phosphaturic effect was due to acidification of final urine or to the decreases in blood $\mathrm{pH}$. Accordingly, in group 7, hamsters were treated with $\mathrm{NH}_{4} \mathrm{Cl}$, and subsequently the urine was alkalinized by $\mathrm{ACZ}$ administration. As in group 6, treatment with $\mathrm{NH}_{4} \mathrm{Cl}$ resulted in a significant decrease in $\mathrm{FEPO}_{4}$; however, the subsequent alkalinization of the final urine with ACZ had no significant effect on $\mathrm{FEPO}_{4}$.

The possibility that acidemia, rather than aciduria, was the primary mechanism for uncovering the phosphaturic effect of PTH was tested in group 8 by the administration of PTH and ACZ concomitantly to $\mathrm{NH}_{4}$ Cl-treated TPTX hamsters. Again, $\mathrm{NH}_{4} \mathrm{Cl}$ resulted in a significant decrease in $\mathrm{FEPO}_{4}$, and $\mathrm{PTH}$ was subsequently markedly phosphaturic in the presence of alkaline urine. In group 9, studies were performed to illustrate that the pretreatment with $\mathrm{NH}_{4} \mathrm{Cl}$ was not necessary to demonstrate the phosphaturic effect of PTH when animals were made acidemic simply by treatment with ACZ. Finally, we returned to the effects of SCT and demonstrated that SCT was also phosphaturic when animals were pretreated with $\mathrm{NH}_{4} \mathrm{Cl}$. Thus, the failure to demonstrate a phosphaturic effect of both PTH and SCT in the hamster could be attributed to the necessity for acidemia to unmask the effect. It is important to note that acidemia alone decreased $\mathrm{FEPO}_{4}$ and that the effect of acidemia on phosphate transport may have been a prerequisite for the subsequent unmasking of hormonal responsiveness. However, it is unlikely that the unmasking of the phosphaturic effect of PTH by $\mathrm{NH}_{4} \mathrm{Cl}$ was due to the reduced $\mathrm{FEPO}_{4}$ per se in the control period, since infusion of calcium resulted in control $\mathrm{FEPO}_{4}$ similar to that after $\mathrm{NH}_{4} \mathrm{Cl}$ infusion, and yet no phosphaturia was elicited by PTH in this group.

Beck et al. reported that increased $\mathrm{FEPO}_{4}$ and UVcAMP after PTH administration was significantly blunted in acidotic rats (17). As in the present studies, tissue cAMP accumulation was significantly lower in slices from acidotic rats. They concluded that the renal response to PTH in the rat is decreased in metabolic acidosis and that this decrease is due to inhibition of PTH-dependent cAMP systems at the level of adenylate cyclase in the renal cortex. In the hamster, the phosphaturic response was unmasked rather than inhibited in acidosis. Thus, the acidosis unmasked a phosphaturic response although cAMP accumulation and in situ protein kinase activation in response to PTH were depressed. This indicates that even in acidosis, cAMP generation and protein kinase activation are sufficient to inhibit phosphate reabsorption, provided that the PTH-sensitive phosphate transport system is made operative by lowering $\mathrm{pH}$.

Unlike a previous report in the rat (18), ACZ had no effect on adenylate cyclase and its activation by PTH. Likewise, there was no effect on cAMP phosphodiesterase. On the other hand, ACZ increased the tissue cAMP accumulation in slices incubated in acidic medium after PTH and either decreased UVcAMP in the absence of PTH or 
abolished its increase after PTH. Consequently, in the presence of ACZ the increased intracellular accumulation of cAMP after PTH is not accompanied by an increase in UVcAMP. Since ACZ did not influence the enzymes of cAMP metabolism, the accumulation of cAMP may have been due to an effect of ACZ on the transcellular movement of cAMP. Regardless of mechanism, this observation indicates that UVcAMP is not always a reliable index of intracellular cAMP metabolism. Thus, the effect of ACZ to potentiate the phosphaturic effect of PTH may be due in part to enhanced tissue accumulation of cAMP. A similar phosphaturic effect of ACZ without increases in UVcAMP was found in patients with hypoparathyroidism or pseudohypoparathyroidism (19).

In conclusion, the lack of a phosphaturic effect of PTH and SCT in hamsters depends on a step in the cellular action of these hormones $(a)$ subsequent to cAMP generation and protein kinase activation and (b) which is dependent upon $\mathrm{pH}$. Thus, this animal may serve as a useful model for studies of various disease states in which the kidney is refractory to the phosphaturic action of PTH in particular and for studies of the relationship between PTH-dependent cAMP action and phosphate transport in general.

\section{ACKNOWLEDGMENTS}

The authors gratefully acknowledge the expert secretarial assistance of Carma Jean Fink and the expert technical assistance of Mrs. Yvonne S. F. Hui.

This study was supported in part by grants from the National Institutes of Health (HL 14133 and AM 16105), by a Grant-in-Aid from the American Heart Association with funds contributed in part by the Minnesota Heart Association, and by the Mayo Foundation.

\section{REFERENCES}

1. Drezner, M., F. A. Neelon, and H. E. Lebovitz. 1973. Pseudohypoparathyroidism type II: A possible defect in the reception of the cyclic AMP signal. N. Engl. J. Med. 289: 1056-1060.

2. Rodriguez, H. J., H. Villarreal, Jr., S. Klahr, and E. Slatopolsky. 1974. Pseudohypoparathyroidism type II: Restoration of normal renal responsiveness to parathyroid hormone by calcium administration. J. Clin. Endocrinol. Metab. 39: 693-701.

3. Hahn, T. J., C. R. Scharp, L. R. Halstead, J. G. Haddad, D. M. Karl, and L. V. Avioli. 1975. Parathyroid hormone status and renal responsiveness in familial hypo- phosphatemic rickets. J. Clin. Endocrinol. Metab. 41: 926-937.

4. Biddulph, D. M., P. F. Hirsch, and P. L. Munson. 1970. Thyrocalcitonin and parathyroid hormone in the hamster. Proceedings of the 2nd International Symposium in Calcitonin. William Heinemann Medical Books, Ltd., London. 392-399.

5. Aurbach, G. D., and D. A. Heath. 1974. Parathyroid hormone and calcitonin regulation of renal function. Kidney Int. 6: 331-345.

6. Dousa, T. P., C. G. Duarte, and F. G. Knox. 1976. Effect of colchicine on urinary phosphate and regulation by parathyroid hormone.Am.J. Physiol. 231: 61-65.

7. Dousa, T. P., and L. D. Barnes. 1974. Effects of colchicine and vinblastine on the cellular action of vasopressin in mammalian kidney. A possible role of microtubules. J. Clin. Invest. 54: 252-262.

8. Wells, J. N., C. E. Baird, Y. J. Wu, and J. G. Hardman. 1975. Cyclic nucleotide phosphodiesterase activities in pig coronary arteries. Biochim. Biophys. Acta. 384: $430-442$.

9. Soderling, T. R., J. D. Corbin, and C. R. Park. 1974. Techniques for the study of protein kinase activation in intact cells. Methods Enzymol. 38: 358-367.

10. Sakai, M., S. Matushita, T. Nakano, N. Kimura, N. Araki, and N. Nagata. 1976. Effects of parathyroid hormone in vivo on the protein kinase activity in rat kidney. Endocrinology. 98: 1443-1450.

11. Corbin, J. D., and E. M. Reimann. 1974. Assay of cyclic AMP-dependent protein kinases. Methods Enzymol. 38: 287-290.

12. Steiner, A. L. 1974. Assay of cyclic nucleotides by radioimmunoassay methods. Methods Enzymol. 38: 96-105.

13. Cuche, J. L., C. E. Ott, G. R. Marchand, J. A. DiazBuxo, and F. G. Knox. 1976. Intrarenal calcium in phosphate handling. Am. J. Physiol. 230: 790-796.

14. Beck, N., H. Singh, S. W. Reed, and B. B. Davis. 1974. Direct inhibitory effect of hypercalcemia on renal actions of parathyroid hormone. J. Clin. Invest. 53: 717-725.

15. Harter, H. R., A. Mercado, W. E. Rutherford, H. Rodriguez, E. Slatopolsky, and S. Klahr. 1974. Effects of phosphate depletion and parathyroid hormone on renal glucose reabsorption. Am. J. Physiol. 227: 1422-1427.

16. Kurokawa, K., N. Nagata, M. Sasaki, and K. Nakane. 1974. Effects of calcitonin on the concentration of cyclic adenosine $3^{\prime}, 5^{\prime}$-monophosphate in rat kidney in vivo and in vitro. Endocrinology. 94: 1514-1518.

17. Beck, N., H. P. Kim, and K. S. Kim. 1975. Effect of metabolic acidosis on renal action of parathyroid hormone. Am. J. Physiol. 228: 1483-1488.

18. Rodriguez, H. J., J. Walls, J. Yates, and S. Klahr. 1974. Effects of acetazolamide on the urinary excretion of cyclic AMP and on the activity of renal adenyl cyclase. J. Clin. Invest. 53: 122-130.

19. Sinha, T. K., D. O. Allen, and N. H. Bell. 1974. Treatment of impaired renal excretion of phosphate in hypoparathyroidism and pseudohypoparathyroidism with acetazolamide. Clin. Res. 22: 620A. (Abstr.) 